\title{
Characterisation of a subtype of colorectal cancer combining features of the suppressor and mild mutator pathways
}

\begin{abstract}
Jeremy R Jass, Kelli G Biden, Margaret C Cummings, Lisa A Simms, Michael Walsh, Estelle Schoch, Stephen J Meltzer, Caroline Wright, Jeffrey Searle, Joanne Young, Barbara A Leggett
\end{abstract}

Department of Pathology, University of Queensland Medical School, Herston Road, Herston, Queensland 4006. Australia J R Jass

M C Cummings

$M$ Walsh

E Schoch

Conjoint

Gastroenterology

Laboratory, Royal

Brisbane Hospital

Foundation Clinical

Research Centre,

Brisbane, Queensland,

Australia

K G Biden

L A Simms

C Wright

J Young

B A Leggett

Department of Pathology, Royal Brisbane Hospital J Searle

Greenbaum Cancer Center, University of Maryland School of Medicine and

Baltimore Veterans Affairs Medical Center, Baltimore, Maryland, USA

S J Meltzer

Correspondence to:

Professor Jass.

email: j.jass@

mailbox.uq.edu.au

Accepted for publication 4 March 1999

\begin{abstract}
Background-10\% of sporadic colorectal cancers are characterised by a low level of microsatellite instability (MSI-L). These are not thought to differ substantially from microsatellite-stable (MSS) cancers, but MSI-L and MSS cancers are distinguished clinicopathologically and in their spectrum of genetic alterations from cancers showing high level microsatellite instability (MSI-H).

Aims-To study the distribution of molecular alterations in a series of colorectal cancers stratified by DNA microsatellite instability.

Methods-A subset of an unselected series of colorectal cancers was grouped by the finding of DNA MSI at 0 loci (MSS) $(n=51), 1-2$ loci $(M S I-L)(n=38)$ and 3-6 loci (MSI-H) $(n=25)$. The frequency of K-ras mutation, loss of heterozygosity $(\mathrm{LOH})$ at $5 \mathrm{q}, 17 \mathrm{p}$ and $18 \mathrm{q}$, and patterns of p53 and $\beta$ catenin immunohistochemistry was determined in the three groups.

Results-MSI-H cancers had a low frequency of K-ras mutation $(7 \%)$, LOH on chromosomes $5 q(0 \%), 17 p(0 \%)$ and $18 q$ $(\mathbf{1 2 . 5 \%})$, and a normal pattern of immunostaining for $p 53$ and $\beta$ catenin. MSI-L cancers differed from MSS cancers in terms of a higher frequency of K-ras mutation (54\% $v 27 \%)(p=0.01)$ and lower frequency of $5 q$ LOH $(23 \% \quad v \quad 48 \%)(p=0.047)$. Whereas aberrant $\beta$ catenin expression and $5 q$ LOH were concordant (both present or both absent) in $57 \%$ of MSS cancers, concordance was observed in only $20 \%$ of MSI-L cancers $(p=0.01)$.

Conclusions-MSI-L colorectal cancers are distinct from both MSI-H and MSS cancers. This subset combines features of the suppressor and mutator pathways, may be more dependent on K-ras than on the APC gene in the early stages of neoplastic evolution, and a proportion may be related histogenetically to the serrated (hyperplastic) polyp.

(F Clin Pathol 1999;52:455-460)
\end{abstract}

Keywords: microsatellite instability; colorectal adenocarcinoma; serrated polyp; ras mutation; loss of heterozygosity

A cancer cell will, in the course of its stepwise progression, accumulate a relatively large number of cancer specific genetic alterations.
In the case of colorectal cancer, many of the early alterations involve the inactivation of tumour suppressor genes, as described by Kinzler and Vogelstein. ${ }^{1}$ Tumour suppressor gene inactivation occurs as a consequence of the state of genetic instability or hypermutability. ${ }^{2}$ This may arise in two main ways. The first is chromosomal instability, manifesting in alterations such as aneuploidy and loss of chromosomal material. This mechanism is associated with loss of heterozygosity (LOH) and accounts for a significant proportion of tumour suppressor gene inactivation (hence "suppressor" pathway). ${ }^{34}$ The second is the more subtle microsatellite instability (MSI) caused by a failure of the DNA mismatch repair system. ${ }^{56}$ The resulting mutations target regions of short unit repetitive DNA and occur not only in the non-coding microsatellite regions of the genome but also in short repetitive tracts within the coding region of genes now known to be implicated in carcinogenesis (TGF $\beta$ RII, IGF2R, BAX, and CDX-2). ${ }^{71}$ This mechanism underlies the "mutator" pathway.

Colorectal cancer may be classified into two major molecular types in which hypermutability occurs either by means of chromosomal instability or MSI. ${ }^{12}$ Not only are different cancer genes implicated in the two types, but MSI cancers are distinguished by their less aggressive behaviour, ${ }^{13}$ predilection for the proximal colon, ${ }^{5}$ tendency to multiplicity, ${ }^{14}$ and possibly in their response to chemotherapeutic agents. ${ }^{15}$

There is now evidence that MSI cancers comprise distinctive MSI-high (H) and MSIlow (L) categories. ${ }^{16-22}$ In MSI-H cancers, at least $40 \%$ of microsatellite loci will show evidence of instability, ${ }^{18-20}$ but the difference is not only quantitative. Some dinucleotide markers (for example D5S346 and D2S123) and compound repeat markers (for example MYCL1) provide sensitive detection for both MSI-H and MSI-L cancers, whereas mononucleotide markers (for example BAT 26 and BAT 40) are more specific for MSI-H cancers. ${ }^{18}{ }^{20}$ MSI-L cancers more closely resemble the MSS (microsatellite stable) or chromosomal instability class of cancers than MSI-H cancers in terms of their mutational profiles and clinicopathological features. ${ }^{1320}$ The DNA mismatch repair genes hMLH1 and hMSH2 do not appear to be implicated in the MSI-L subset. ${ }^{181921}$ On the other hand there is evidence of molecular differences between MSI-L and MSS colorectal cancers apart from 
the mild mutator phenotype. Konishi et al reported a higher frequency of K-ras mutation in MSI-L cancers ${ }^{17}$ while Biden et al showed reduced expression of BCL-2 protein in MSI-L cancers. ${ }^{23}$

The MSI-L phenotype occurs with increased frequency in particular types of colorectal polyps-hyperplastic polyps, serrated adenomas, and mixed polyps. ${ }^{24}$ We have suggested that the MSI-L phenotype characterises a distinct morphogenetic subtype of colorectal cancer in which hypermutability is driven by a combined suppressor and mild mutator mechanism. ${ }^{24}$ In order to test this hypothesis further, we have studied genetic alterations in a series of MSS, MSI-L, and MSI-H colorectal cancers, specifically K-ras mutation, $5 \mathrm{q} \mathrm{LOH}$, $17 \mathrm{p} \mathrm{LOH}, 18 \mathrm{q} \mathrm{LOH}$, and the immunohistochemical expression of $\mathrm{p} 53$ and $\beta$ catenin. The findings support the concept of a third category of colorectal cancer.

\section{Methods}

SAMPLES

This study was carried out on a subset of 115 tumours which were part of a series of 303 sporadic colorectal cancers characterised previously according to their level of DNA microsatellite instability. ${ }^{20}$ Of these, 26 were MSI-H, 38 were MSI-L, and the remaining 51 were MSS.

MUTATION AND LOH ANALYSES

DNA was extracted from fresh tumour samples as described previously. ${ }^{20}$ Mutations in codons 12 and 13 of the K-ras proto-oncogene were detected using the non-radioactive polymerase chain reaction-restriction fragment length polymorphism (PCR-RFLP) method described by Bell et al. ${ }^{25}$ The frequency of allelic loss was analysed on chromosomes 5q (APC gene), 17p (p53 gene), and 18q (DCC, DPC4, MadR2 gene cluster). On chromosome 5q, loss was assessed using the microsatellite marker D5S346, and the intragenic APC PCR-RFLP markers FAP58, FAP37, and FB54D. Loss was assessed on chromosome $17 \mathrm{p}$ as previously described, using two polymorphic markers contained within the $\mathrm{p} 53$ gene: one microsatellite from intron 1 and a PCR-RFLP from exon $10^{23}$; and on $18 \mathrm{q}$ a group of four microsatellite markers was used (D18S68, D18S64, D18S851, and D18S460) as well as an intragenic DCC PCR-RFLP marker. ${ }^{26}$

For microsatellite markers, PCR incorporation of ${ }^{33} \mathrm{P}$-dATP was performed in a total reaction volume of $20 \mu \mathrm{l}$. Amplified products were separated on $5 \%$ denaturing polyacrylamide gels (19:1 acrylamide:bisacrylamide; Bio$\mathrm{Rad})$, run at $65 \mathrm{~W}$ for 1.5 to 2 hours, dried, and then exposed to $x$ ray film (X-OMAT-AR, Kodak) for four to six days. For RFLP markers, unlabelled PCR products were digested for two hours with marker specific restriction enzymes according to the manufacturer's instructions. Aliquots $(8 \mu \mathrm{l})$ were then electrophoresed on $10 \%$ denaturing polyacrylamide mini-gels (29:1 acrylamide:bisacrylamide; Bio-Rad), run at $125 \mathrm{~V}$ for 1.5 to 2 hours, and stained in 0.5 $\mu \mathrm{g} / \mathrm{ml}$ ethidium bromide for five minutes. Allelic loss was scored visually and conservatively in all heterozygotes by two independent observers. Mutations in $\beta$ catenin were sought in a subset of MSI-L tumours according to the method of Sparks et $a l,{ }^{27}$ using ${ }^{33} \mathrm{P}$ labelled ddNTPs and manual direct sequencing.

IMMUNOHISTOCHEMISTRY

For p53 and $\beta$ catenin immunohistochemistry, paraffin sections $(4 \mu \mathrm{m})$ were affixed to charged adhesive slides and air dried overnight at $37^{\circ} \mathrm{C}$. Sections were dewaxed and rehydrated through ascending grades of alcohol to Tris buffered saline (TBS), $\mathrm{pH}$ 7.4. Heat based antigen retrieval was performed using the technique of Shi et al. ${ }^{28}$

The sections were boiled for five minutes in $0.01 \mathrm{M}$ citric acid buffer, $\mathrm{pH} 6.0$, in a domestic $600 \mathrm{~kW}$ microwave. After transferring the sections to fresh citric acid buffer, the sections were again boiled for five minutes, then taken from the microwave and permitted to cool for approximately 30 minutes before being washed in three changes of TBS for five minutes each.

Endogenous peroxidase activity was quenched in $1 \% \mathrm{H}_{2} \mathrm{O}_{2}, 0.1 \%$ sodium azide in TBS. After washing three times for five minutes in TBS, non-specific antibody binding was blocked by incubating the sections in $4 \%$ commercial skim milk powder for 15 minutes. After brief rinsing in TBS, the sections were transferred to a humidified chamber and incubated overnight in goat polyclonal anti- $\beta$ catenin antibody (Santa-Cruz Biotechnology) diluted 1:750, or mouse monoclonal p53 (clone DO7, Dako) diluted 1:100 in TBS.

The sections were then thoroughly washed in three changes of TBS for five minutes each. The $\beta$ catenin sections were incubated with biotinylated donkey antigoat secondary antibody (diluted 1:400 in TBS) (Jackson ImmunoResearch Laboratories) and the p53 sections with goat antimouse antibody (Zymed Corporation). This was followed by prediluted streptavidin horseradish peroxidase conjugate (Zymed Corporation) for 15 minutes. Antigenic sites were revealed using $0.05 \%$ 3,3'diaminobenzidine in Tris saline with $\mathrm{H}_{2} \mathrm{O}_{2}$ as a substrate.

The sections were lightly counterstained in haematoxylin, then dehydrated, cleared, and mounted using DPX. Negative and positive controls were used in all staining runs.

Scoring was performed by two pathologists with no knowledge of the MSI status of the tumours. Scoring of $\beta$ catenin was based upon the distribution of $\beta$ catenin within the cell membrane (0-1), cytoplasm (0-2), and nuclei $(0-2)$, with a total score of 0 reflecting cell membrane staining only, similar to that seen in normal colonic mucosa, up to an aggregate score of 5 for tumours with strong nuclear staining (2), diffuse cytoplasmic staining (2), and loss of cell membrane staining (1). Total scores were then collapsed into three grades (grade I, 0-1; grade II, 2-3; grade III, 4-5). Nuclear p53 was scored as $0(<5 \%), 1$ $(6-25 \%), 2(26-50 \%), 3(51-75 \%)$, and 4 $(>75 \%)$. When the observers differed for the 

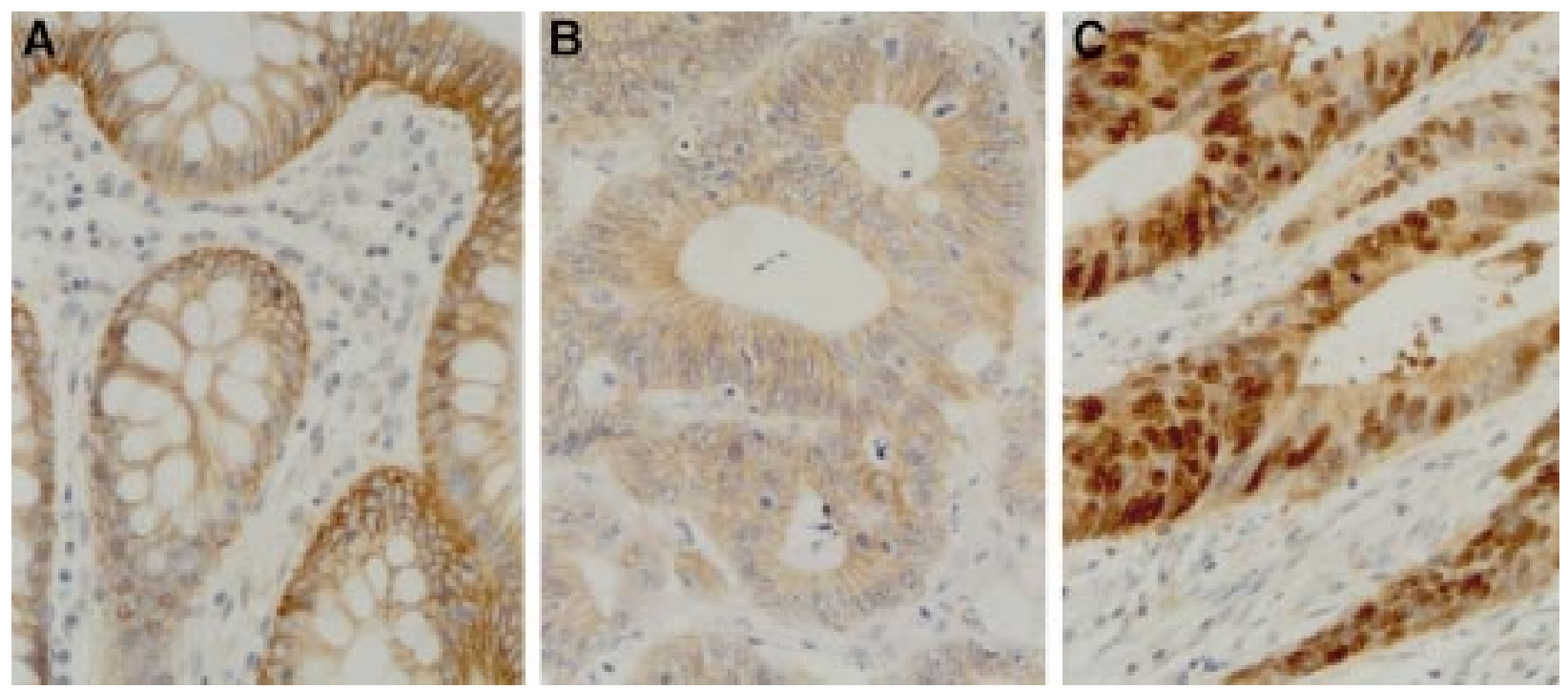

Figure 1 Immunohistochemical expression of $\beta$ catenin in normal and malignant epithelium. Normal colorectal mucosa ( $A$ ), an MSI-H cancer (high level microsatellite instability) (B), and MSS cancer (microsatellite-stable) (C). In both (A) and (B) staining is limited to the cell membranes.

Intra-epithelial (tumour infiltrating) lymphocytes are present within the MSI-H cancer (B), a relatively specific biomarker. ${ }^{20}$ The staining pattern in (B) was scored 0 and the cancer did not show $5 q$ loss of heterozygosity $(5 q \mathrm{LOH})$. In the MSS cancer (C), cell membrane staining has disappeared. There is diffuse cytoplasmic staining and intense nuclear staining (overall score 5). The cancer showed $5 q$ LOH. (Immunoperoxidase staining.)

final grading, cases were discussed over a double headed microscope and the final grade reached by consensus.

\section{Results}

The results of K-ras mutation, loss of heterozygosity, and immunohistochemistry analyses are summarised in table 1 . Overall, K-ras mutations were found in $30 \%(72 / 244)$ of the tumour cohort described by Jass et al. ${ }^{20}$ When these tumours were analysed by microsatellite instability level, $4 \%$ of MSI-H (1/28), $43 \%$ of MSI-L (16/37), and 30\% of MSS (54/179) showed mutations in K-ras. When the subset of tumours studied in this current report was analysed, $7 \%$ of MSI-H (2/26), $54 \%$ of MSI-L (19/38), and $27 \%$ of MSS (13/48) showed mutations in K-ras, representing a significant difference between the three classes

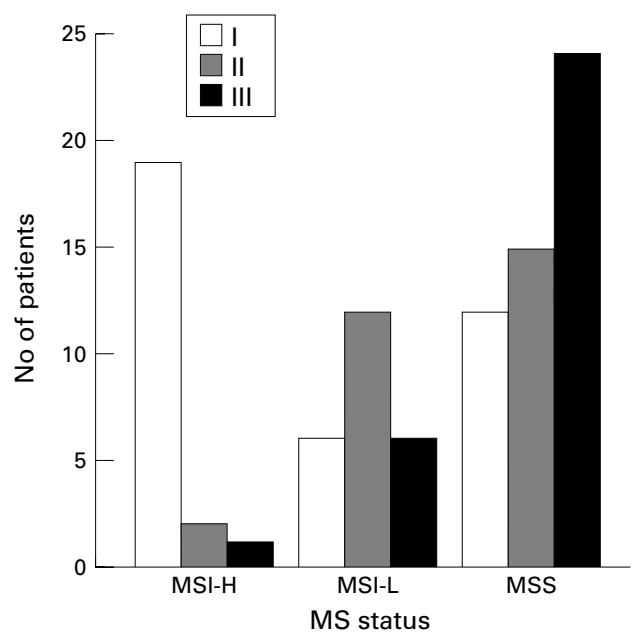

Figure 2 Distribution of $\beta$ catenin grades in MSI-H (high level microsatellite instability), MSI-L (low level microsatellite instability), and MSS (microsatellite-stable) cancers. The variation between microsatellite classes with respect to distribution of $\beta$ catenin grades was significant $\left(p<0.0001 ; \chi^{2}\right.$ analysis). Grade I, score 0-1; grade II, score 2-3; grade III, score 4-5.
( $\mathrm{p}=0.0004, \chi^{2}$ analysis). In addition, the rate of K-ras mutation was higher in the MSI-L group than in the MSS cancers $\left(p=0.01, \chi^{2}\right.$ analysis). A strong trend was evident when chromosome $5 \mathrm{q} \mathrm{LOH}$ was compared in the three classes ( $\mathrm{p}=0.0001$, Wilcoxon rank sum test). Comparisons of MSI-L ( $25 \%$, or $8 / 32$ ) and MSS (48\%, or 20/42) showed that chromosome $5 \mathrm{q} \mathrm{LOH}$ occurred less often in MSI-L tumours ( $\mathrm{p}=0.047, \chi^{2}$ analysis). Loss of heterozygosity at $17 \mathrm{p}$ and $18 \mathrm{q}$ was rare in MSI-H tumours, though it occurred with similar frequency in MSI-L and MSS cancers.

Immunohistochemistry scores for $\mathrm{p} 53$ and $\beta$ catenin showed significant differences between MSI-H cancers and MSI-L/MSS cancers $(\mathrm{p}<0.01$ in both cases, Student's $t$ test). Examples of $\beta$ catenin immunohistochemistry

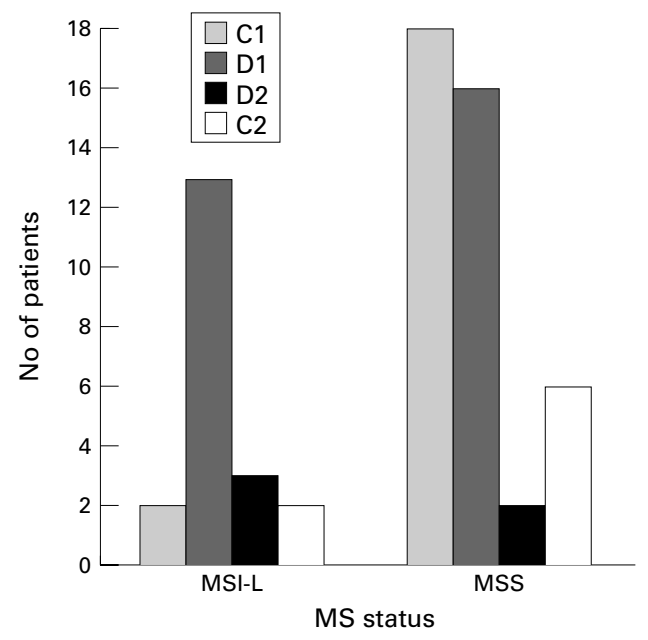

Figure 3 Distribution within MSI-L and MSS cancers of concordant (C) and discordant (D) relations between $\beta$ catenin grade and $5 q$ loss of heterozygosity $(5 q \mathrm{LOH})$. Significantly more discordance is seen in MSI-L cancers $(p=0.0059$, Fisher's exact test). Concordant patterns $(C 1=\beta$ catenin grade II-III/5q LOH positive; $C 2=\beta$ catenin grade I/5q LOH negative). Discordant patterns $(D 1=\beta$ catenin grade II-III $/ 5 q$ LOH negative; $D 2=\beta$ catenin grade I/5q LOH positive). 
staining are illustrated in fig 1. Distribution of $\beta$ catenin grades showed significant variation between microsatellite classes $\left(\mathrm{p}<0.0001 ; \chi^{2}\right.$ analysis) (fig 2). $\beta$ Catenin scores were higher in MSS than in MSI-L cancers but the difference was not significant (table 1). When loss of heterozygosity at $5 \mathrm{q}$ was compared with $\beta$ catenin expression within the MSI-L and MSS classes, discordant results were observed more often in the MSI-L class ( $p=0.0059$, Fisher's exact test) (fig 3). No MSI-L discordant tumours showed activating mutations in $\beta$ catenin.

\section{Discussion}

The mild mutator phenotype or MSI-L is characterised by microsatellite instability occurring in less than $40 \%$ of loci, and mostly involving repeat sequences other than those comprising mononucleotide runs. ${ }^{18-22}$ Apart from showing mild levels of microsatellite instability (which led to the initial bracketing of MSI-L and MSI-H cancers), MSI-L cancers appear to have more in common with MSS than MSI-H cancers (table 1). This is particularly evident with respect to the infrequency or lack of mutation of the genes TGF $\beta$ RII, IGF2R, BAX, and CDX-2 in both MSI-L and MSS cancers (table 2). ${ }^{11}{ }^{20}$ Furthermore, the frequency of $17 \mathrm{p}$ and $18 \mathrm{q} \mathrm{LOH}$ is similar in MSS and MSI-L cancers but absent or significantly reduced in MSI-H cancers. ${ }^{17}$ However, MSI-L cancers have previously been distinguished from MSS cancers on the basis of a higher frequency of K-ras mutation ${ }^{17}$ and reduced expression of BCL-2. ${ }^{23}$ Our present study has confirmed and extended these observations.

Several reports have suggested that APC mutations may be rare in MSI-H

Table 1 Distribution of genetic alterations by microsatellite status

\begin{tabular}{lccclll}
\hline & $\begin{array}{l}\text { K-ras codons } \\
12 \text { and 13 }\end{array}$ & $5 q$ LOH & $17 p$ LOH & $18 q$ LOH & $\begin{array}{l}\text { Mean } \beta \\
\text { catenin score }\end{array}$ & $\begin{array}{l}\text { Mean } \\
p 53 \text { score }\end{array}$ \\
\hline MSI-H & $7 \%(2 / 26)^{\star}$ & $0 \%(0 / 20)$ & $0 \%(0 / 12)$ & $12.5 \%(2 / 16)$ & 0.818 & 0.79 \\
MSI-L & $54 \%(19 / 38)$ & $25 \%(8 / 32)$ & $57 \%(16 / 28)$ & $77 \%(17 / 22)$ & 2.416 & 2.34 \\
MSS & $27 \%(13 / 48)$ & $48 \%(20 / 42)$ & $58 \%(26 / 45)$ & $71 \%(35 / 49)$ & 2.960 & 2.33 \\
\hline
\end{tabular}

*Numbers in parenthesis indicate the number of cancers with a genetic alteration out of the informative cases. MSI-H, high level microsatellite instability; MSI-L, low level microsatellite instability; MSS, microsatellite-stable; LOH, loss of heterozygosity.

Table 2 Molecular and evolutionary profiles of colorectal cancer

\begin{tabular}{|c|c|c|c|c|}
\hline & $M S S$ & $M S I-L$ & $M S I-H$ & References* \\
\hline 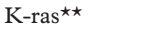 & ++ & +++ & + & [17] [43]‡ \\
\hline $5 \mathrm{qLOH}$ & +++ & + & $+/-$ & {$[17] \ddagger$} \\
\hline $17 \mathrm{p} \mathrm{LOH}$ & +++ & +++ & $+/-$ & [17] [43] \\
\hline $18 \mathrm{qLOH}$ & +++ & +++ & + & [17] [43] \\
\hline TGF $\beta$ III $^{\star \star}$ & + & $?$ & +++ & [7] [17] [20][29] \\
\hline IGF2R ${ }^{\star \star}$ & - & - & + & [8] [20] \\
\hline $\mathrm{BAX}^{\star \star}$ & - & - & ++ & [9] [10] [20] \\
\hline $\mathrm{CDX} 2^{\star \star}$ & - & - & + & {$[11]$} \\
\hline p53 $3^{\star \star \star}$ & +++ & +++ & $+/-$ & [10] [43] \\
\hline BCL-2† & +++ & + & + & [23] \\
\hline$\beta$ Catenin $\dagger$ & +++ & ++ & + & $\ddagger$ \\
\hline $\begin{array}{l}\text { Precancerous } \\
\text { lesion }\end{array}$ & Adenoma & $\begin{array}{l}\text { Serrated } \\
\text { adenoma }\end{array}$ & Adenoma & [24] [44] [45] \\
\hline
\end{tabular}

${ }^{\star}$ The list includes landmark references and/or recent references classifying colorectal cancer as MSS (microsatellite-stable), MSI-L (low level microsatellite instability), and MSI-H (high level microsatellite instability).

${ }^{\star \star}$ Mutation.

$\star \star \star$ Mutation and immunohistochemistry.

†Immunohistochemistry.

$\ddagger$ Present study. tumours. ${ }^{17} 3031$ Our findings support this view, since $\beta$ catenin staining patterns in MSI-H cancers resembled those seen in normal colonic mucosa, and loss of heterozygosity on chromosome $5 \mathrm{q}$ was rare. Conversely, high levels of $5 \mathrm{q} \mathrm{LOH}$ and nuclear staining for $\beta$ catenin were found in the MSS group. An intermediate level of chromosome $5 \mathrm{q} \mathrm{LOH}$ was observed in MSI-L tumours. This relatively low level of chromosome $5 \mathrm{q} \mathrm{LOH}$ was obtained despite the use of four polymorphic markers which rendered 32 of the 38 MSI-L tumours informative. Konishi et al also found less $5 \mathrm{q} \mathrm{LOH}$ in MSI-L than MSS cancers, but the difference was small and not significant. ${ }^{17}$ Of particular interest in our study was the discordance between allelic loss on $5 \mathrm{q}$ and abnormal $\beta$ catenin expression in the MSI-L tumour class. Although it has been reported that between $12 \%$ and $48 \%$ of colorectal tumours that do not carry APC mutations show activating mutations in $\beta$ catenin, ${ }^{27}{ }^{32}$ such mutations were not found in the discordant tumours in this study. It is more likely that inactivation of the wild-type APC allele occurs preferentially by mutation rather than by allelic loss in MSI-L cancers. This is suggested by the findings of Konishi et al, ${ }^{17}$ who reported a high frequency of APC mutation in MSI-L colorectal cancers.

When complexed with products of the Tcf gene family, $\beta$ catenin functions as a transcriptional activator. ${ }^{33}$ The tumour suppressor gene APC serves as a "gatekeeper" through its control of $\beta$ catenin-Tcf signalling. ${ }^{1}$ Inactivation of APC in human colorectal cancer leads to uncontrolled $\beta$ catenin accumulation and increased transcription of target genes for hTcf- $4 . .^{34}$ In this study aberrant $\beta$ catenin immunostaining, specifically a switch from an exclusively cell membrane pattern of localisation to diffuse cytoplasmic and nuclear staining (fig 1), was employed as a surrogate for APC loss. The correlation between altered $\beta$ catenin immunostaining and $5 \mathrm{q} \mathrm{LOH}$ in MSS cancers supports the use of $\beta$ catenin immunohistochemistry for this purpose.

APC mutation is thought to initiate the development of dysplastic aberrant crypt foci or microadenomas, ${ }^{36}$ whereas K-ras mutation occurs during adenoma progression, if at all. ${ }^{37}$ On the other hand, aberrant crypt foci comprising hyperplastic (non-dysplastic) epithelium may be initiated by K-ras mutation. ${ }^{36}$ K-ras mutations within hyperplastic epithelium have been reported to occur at frequencies ranging from $12.5 \%$ to $75 \% .{ }^{36}{ }^{38-40}$ The reported frequency of K-ras mutation in serrated adenomas is similarly wide, ranging from $5 \%{ }^{41}$ to $57 \%{ }^{40}$ The fact that K-ras mutation may initiate the process of serrated hyperplasia, but is not found in all samples of hyperplastic epithelium, points to the operation of other unknown genetic mechanisms that would serve as surrogates. Nevertheless, the high frequency of K-ras mutation in MSI-L cancers raises the possibility of a histogenetic link with hyperplastic polyp and serrated adenoma, lesions which may also show the MSI-L phenotype. ${ }^{24}$ The K-ras findings are in agreement with those of Konishi et al. ${ }^{17}$ In their study of 106 sporadic 


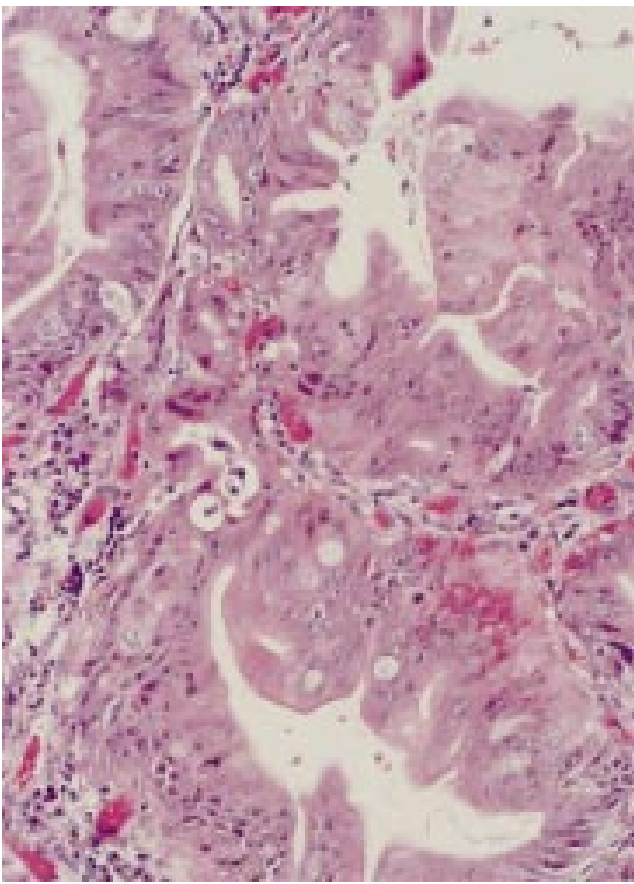

Figure 4 Superficial zone of an MSI-L cancer showing serrated crypts lined by columnar cells with abundant eosinophilic cytoplasm and relatively small vesicular nuclei and scattered goblet cells. The cytological appearances strongly recall the hyperplastic (metaplastic) polyp of the colorectum, lesions that may show the MSI-L phenotype. ${ }^{24}$ (Haematoxylin and eosin.)

colorectal cancers, K-ras mutations were found in $50 \%$ of MSI-L and $30 \%$ of MSS tumours which had been classified according to criteria similar to those of the present report.

It could be argued that MSI-L cancers are merely heterogeneous, some being like MSI-H and others like MSS cancers. While this would fit with the intermediate findings for $5 \mathrm{q} \mathrm{LOH}$, it does not explain the increased frequency of K-ras mutation, the discordance between $5 \mathrm{q}$ $\mathrm{LOH}$ and abnormal $\beta$ catenin expression, the mild mutator phenotype, and the marked clinicopathological differences between MSI-L and MSI-H cancers. ${ }^{20}$ The separation of MSI-L and MSS colorectal cancers is supported by significant differences in elements of three independent molecular pathways: Wnt signalling (APC/ $\beta$ catenin), K-ras, and BCL-2. ${ }^{23}$ We therefore suggest that MSI-L cancers should be distinguished as a subset combining features of the suppressor and mild mutator pathways. We also hypothesise that a proportion of MSI-L cancers arises through the morphogenetic sequence hyperplastic polyp-serrated adenoma. ${ }^{24}$ One of the MSI-L cancers showed the typical architectural and cytological appearances of a hyperplastic polyp (fig 4). Such serrated adenocarcinomas have been reported previously, including their shared functional phenotypes with hyperplastic polyps. ${ }^{42}$ No other MSI-L cancer showed this pattern, perhaps because subclonal progression had resulted in obliteration of this phenotype and convergence with the more conventional morphology of colorectal adenocarcinoma.

By separating MSI-H and MSI-L cancers, the former are shown to be associated with a molecular profile that overlaps only minimally with MSS and MSI-L cancers (tables 1 and 2). The higher frequency of K-ras mutation in MSI cancers reported in some studies is explained at least in part by the failure to distinguish MSI-H (low K-ras) and MSI-L (high K-ras) cancers. ${ }^{43}$ Kinzler and Vogelstein ${ }^{1}$ have presented a unified model to explain the evolution of colorectal cancer regardless of the mechanism of genetic instability. It now seems likely that this evolution is more complex. The early events driving the MSI-H pathway are still unclear, particularly the initiating stages in which APC has been viewed as a "gatekeeper." The low frequency of both $5 \mathrm{q} \mathrm{LOH}$ and abnormal $\beta$ catenin expression in MSI-H cancers suggests that a surrogate mechanism is operating at the stage of adenoma initiation for this subgroup. The adenoma-carcinoma sequence is thought to operate in at least a proportion of MSI-H cancers, whether sporadic $^{44}$ or occurring in the context of hereditary non-polyposis colorectal cancer, ${ }^{45}$ and may implicate genes other than APC or $\beta$ catenin, though conceivably associated with this signalling pathway. Furthermore, since there is little evidence of inactivation of $\mathrm{p} 53$ or genes located on 18q, MSI-H cancers maintain their separate developmental pathway throughout their history.

We suggest that there are at least three mechanisms underlying the evolution of colorectal cancer. The MSI-H pathway differs from the outset, whereas the differences between MSI-L and MSS relate largely to the stages of initiation and early progression. Convergence occurs between MSI-L and MSS cancers at the adenoma-carcinoma transition, as these cancers share common levels of mutation with respect to $17 \mathrm{p}$ (p53) and $18 \mathrm{q} \mathrm{LOH}$. The recognition of a novel suppressor/mild mutator (MSI-L) pathway underlying a third category of colorectal cancer is of potential importance. There is evidence of increased tumour aggression in the MSI-L subset, as indicated by the frequency of distant metastase ${ }^{20}$ as well as by the high rate of K-ras mutation. The latter is an important adverse prognostic factor, and specific mutations are correlated with distant spread. ${ }^{46-49}$ The possibility of there being a fundamental difference in the early evolution of this subset points to a separate aetiology. Attempts to define the cause of colorectal cancer have to date met with only partial success, perhaps because the disease is heterogeneous. We suggest that the classification of colorectal cancer into MSS, MSI-L, and MSI-H, while of importance in relation to prognosis and management, may be of particular value in epidemiological research. The mechanism initiating the mild mutator pathway may be revealed in the same way as the mechanisms underlying the MSS (APC) and MSI-H (DNA mismatch repair genes) pathways, namely the investigation of MSI-L cancer families. Familial hyperplastic polyposis would be an obvious condition with which to begin genetic linkage studies. $^{50}$

We wish to acknowledge the support of the following: Queensland Cancer Fund, National Health and Medical Research 
Council, Walter Paulsen Memorial Tumour Bank and Royal Brisbane Hospital Research Foundation. During this work, JY was supported by the Department of Pathology at Royal
Brisbane, and SIM by NIH Grants CA77057 and DK47717. Secretarial support was provided by B Mason.

1 Kinzler K, Vogelstein B. Lessons from hereditary colon cancer. Cell 1996;87:159-70.

2 Nowell PC. The clonal evolution of tumor cell population Science 1976;194:23-8.

3 Hartwell L. Defects in a cell cycle checkpoint may be responsible for the genomic instability of cancer cells. Cell 1992;71:543-6.

4 Cahill DP, Lengauer C, Yu J, et al. Mutations of mitotic checkpoint genes in human cancers. Nature 1998;392:300-

5 Thibodeau SN, Bren G, Schaid D. Microsatellite instability in cancer of the proximal colon. Science 1993;260:816-19.

6 Ionov Y, Peinado MA, Malkhosyan S, et al. Ubiquitous somatic mutations in simple repeated sequences reveal a new mechanism for colonic carcinogenesis. Nature 1993 363:558-61.

7 Markowitz S, Wang J, Myeroff L, et al. Inactivation of the type II TGF- $\beta$-receptor in colon cancer cells with microstype II TGF- $\beta$-receptor in colon cancer cell
atellite instability. Science 1995;268:1336-8.

8 Souza RF, Appel R, Yin J, et al. The insulin-like growth factor II receptor gene is a target of microsatellite instability in human gastrointestinal tumours. Nature Genet 1996;14: 255-7.

9 Rampino N, Yamamoto $\mathrm{H}$, Ionov $\mathrm{Y}$, et al. Somatic frameshift mutations in the BAX gene in colon cancers of the microsatellite mutator phenotype. Science 1997;275 967-9.

10 Simms LA, Radford-Smith G, Biden KG, et al. Reciprocal relationship between tumor suppressor p53 and BAX in primary colorectal cancers. Oncogene 1998;17:2003-8.

11 Wicking C, Simms LA, Evans T, et al. CDX2, a human homologue of Drosophila caudal, is mutated in both alleles in a replication error positive colorectal cancer. Oncogene 1998;17:657-9.

12 Perucho $M$. Cancer of the microsatellite mutator phenotype. F Biol Chem 1996;377:675-84.

13 Lothe RA, Peltomäki P, Meling GI, et al. Genomic instability in colorectal cancer: relationship to clinicopathological ity in colorectal cancer: relationship to clinicopathological
variables and family history. Cancer Res 1993;53:5849-52.

14 Horii A, Han HJ, Shimada M, et al. Frequent replication errors at microsatellite loci in tumors of patients with mulerrors at microsatellite loci in tumors of patients with

15 Carethers JM, Hawn MT, Chauhan DP, et al. Competency in mismatch repair prohibits clonal expansion of cancer cells treated with $\mathrm{N}$-methyl-N'-nitro-N-nitrosoguanidine. $\mathcal{F}$ Clin Invest 1996;98:199-206.

16 Ishimaru G, Adachi JI, Shiseki M, et al. Microsatellite instability in primary and metastatic colorectal cancers. Int $\mathcal{F}$ Cancer 1995;64:153-7.

17 Konishi M, Kikuchi-Yanoshita R, Tanaka K, et al. Molecular nature of colon tumors in hereditary nonpolyposis colon cancer, familial polyposis, and sporadic colon cancer. Gastroenterology 1996;111:307-17.

18 Dietmaier W, Wallinger S, Bocker T, et al. Diagnostic microsatellite instability: definition and correlation with mismatch atelite instability: definition and correlation with mism

19 Bocker T, Diermann J, Friedl W, et al.. Microsatellite instability analysis: a multicenter study for reliability and quality control Cancer Res 1997;57:4739-43.

20 Jass JR, Do K-A, Simms LA, et al. Morphology of sporadic colorectal cancer with DNA replication errors. Gut

21 Thibodeau SN, French AJ, Cunningham JM, et al. Microsatellite instability in colorectal cancer: different mutato phenotypes and the principle involvement of hMLH1. Cancer Res 1998;58:1713-18.

22 Percesepe A, Kristo P, Aaltonen LA, et al. Mismatch repair genes and mononucleotide tracts as mutation targets in colorectal tumors with different degrees of microsatellite instability. Oncogene 1998;17:157-63.

23 Biden KG, Simms LA, Cummings M, et al. Expression of $\mathrm{Bcl}-2$ protein is decreased in colorectal adenocarcinomas

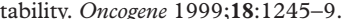

24 Iino H, Jass JR, Simms LA, et al. DNA microsatellite instability in hyperplastic polyps, serrated adenomas, and mixed polyps: a mild mutator pathway for colorectal cancer? $\mathcal{f}$ polyps: a mild mutator

25 Bell SM, Kelly SA, Hoyle JA, et al. c-Ki-ras gene mutations in dysplasia and carcinomas complicating ulcerative colitis. $B r \mathcal{F}$ Cancer 1991;64:174-8.
26 Huang Y, Boynton RF, Blount PL, et al. Loss of heterozygosity involves multiple tumor suppressor genes in human esophageal cancers. Cancer Res 1992;52:6525-30.

27 Sparks AB, Morin PJ, Vogelstein B, et al. Mutational analysis of the APC/beta-catenin/Tcf pathway in colorectal cancer. Cancer Res 1998;58:1130-4.

$28 \mathrm{Shi}, \mathrm{SR}$, Key ME, Kalra KL. Antigen retrieval in formalinfixed, paraffin embedded tissues: an enhancement method for immunohistochemical staining based upon microwave oven heating of tissue sections. F Histochem Cytochem 1991; 39:741-8.

29 Grady WM, Myeroff LL, Swinler SE, et al. Mutational inactivation of transforming growth factor $b$ receptor type II in microsatellite stable colon cancers. Cancer Res 1999;59: $320-4$.

30 Heinen CD, Richardson D, White R, et al. Microsatellite instability in colorectal adenocarcinoma cell lines that have full-length adenomatous polyposis coli protein. Cancer Res 1995;55:4797-9.

31 Olschwang S, Hamelin R, Laurent-Puig P, et al. Alternative genetic pathways in colorectal carcinogenesis. Proc Natl Acad Sci USA 1997;94:2122-7.

32 Iwao K, Nakamori S, Kameyama M, et al. Activation of the beta-catenin gene by interstitial deletions involving exon 3 in primary colorectal carcinomas without adenomatous polyposis coli mutations. Cancer Res 1998;58:1021-6

33 Molenaar M, van de Wetering M, Oosterwegel M, et al. Tcf-3 transcription factor mediates $\beta$-catenin-induced axis formation in Xenopus embryos. Cell 1996;86:391-9.

34 Korinek V, Barker N, Morin PJ, et al. Constitutive transcriptional activation by a $\beta$-catenin-Tcf complex in APC colon carcinoma. Science 1997;275:1784-7.

35 Morin PJ, Sparks AB, Korinek V, et al. Activation of beta-atenin-Tcf signaling in colon cancer by mutations in beta-atenin-T cf signaling in colon cancer by mut
beta-catenin or APC. Science 1997;275:787-90.

36 Jen J, Powell SM, Papadopoulos N, et al. Molecular determinants of dysplasia in colorectal lesions. Cancer Res 1994;54:5523-6.

37 Vogelstein B, Fearon ER, Hamilton SR, et al. Genetic alterations during colorectal-tumor development. $N$ Engl f Med 1988;319:525-32.

38 Uchida $\mathrm{H}$, Ando $\mathrm{H}$, Maruyama $\mathrm{K}$, et al. Genetic alterations of mixed hyperplastic adenomatous polyps in the colon and rectum. Fpn f Cancer Res 1998;89:299-306.

39 Otori K, Oda Y, Sugiyama K, et al. High frequency of K-ras mutations in human colorectal hyperplastic polyps. Gut 1997;40:660-3.

40 Hiyama T, Yokozaki H, Shimamoto F, et al. Frequent p53 gene mutations in serrated adenomas of the colorectum. $\mathcal{F}$ Pathol 1998;186:131-9.

41 Ajioka Y, Watanabe H, Jass JR, et al. Infrequent K-ras codon 12 mutation in serrated adenomas of human colorectum. Gut 1998;42:680-4.

42 Jass JR, Smith $M$. Sialic acid and epithelial differentiation in colorectal polyps and cancer-a morphological, mucin and lectin histochemical study. Pathology 1992;24:233-42.

43 Fujiwara T, Stolker JM, Watanabe T, et al. Accumulated clonal genetic alterations in familial and sporadic colorectal carcinomas with widespread instability in microsatellite sequences. Am f Pathol 1998;153:1063-78.

44 Grady WM, Rajput A, Myeroff L, et al. Mutation of the type II transforming growth factor- $\beta$ receptor is coincident with the transformation of human colon adenomas to malignant carcinomas. Cancer Res 1998;58:3101-4.

45 Jass JR, Stewart SM. Evolution of hereditary non-polyposis colorectal cancer. Gut 1992;33:783-6.

46 Benhattar J, Losi L, Chaubert P, et al. Prognostic significance of K-ras mutations in colorectal carcinoma. Gastroenterology 1993;104:1044-8.

47 Finkelstein SD, Sayegh R, Christensen S, et al. Genotypic classification of colorectal adenocarcinoma. Biologic behavior correlates with K-ras-2 mutation type. Cancer 1993; 71:3827-33

48 Tanaka M, Omura K, Watanabe Y, et al. Prognostic factors of colorectal cancer: K-ras mutation, overexpression of the p53 protein, and cell proliferative activity. F Surg Oncol 1994;57:57-64.

49 Elnatan J, Goh HS, Smith DR. C-Ki-Ras activation and the biological behaviour of proximal and distal colonic adenocarcinomas. Eur 7 Cancer 996;32A:491-7.

50 Jeevaratnam P, Cottier DS, Browett PJ, et al. Familial giant hyperplastic polyposis predisposing to colorectal cancer: a $1996 ; 179$ 20-5. 